\title{
Migração internacional e desenvolvimento econômico
}

\author{
JAN BRZOZOWSKI
}

\section{Introdução}

A MIGRAÇÃo está presente na história do ser humano desde o seu começo: as primeiras relações sobre os movimentos populacionais podem ser encontrados na Bíblia e outras fontes históricas da Antiguidade. O êxodo dos judeus do antigo Egito (aproximadamente em 1200 a.C.), a migração dos gregos na região mediterrânea (desde 800 a.C.) são apenas alguns exemplos desses processos. Os homens migravam sempre, porém desde o século XIX pode-se observar a intensificação dos movimentos populacionais no quadro mundial. Nos anos 1815-1930, aproximadamente 52 milhões de europeus emigraram rumo a ambas as Américas - incluindo o Brasil. ${ }^{1} \mathrm{~A}$ migração adquire assim caráter maciço: o século XX foi descrito por alguns pesquisadores como "época da migração" (cf. Castles \& Miller, 2009). Durante apenas cinco décadas, o número de migrantes internacionais quase triplicou, de 76 milhões em 1960, para 214 milhões em $2010^{2}$ (IOM, 2008; Desa, 2009). Nesse período, que abrangeu duas guerras mundiais, decolonização e guerra fria, ocorreram mudanças profundas na economia mundial que também influenciaram o padrão migratório dos muitos países e regiões: tanto receptores como emissores. Nesse sentido, a transformação do padrão migratório que ocorreu no Brasil nas décadas de 1980 e 1990 faz parte de um processo mais universal. A Europa Ocidental, que por mais de um século era a principal região exportadora da mão de obra, após 1945 começa a se tornar uma importante área receptora de imigração, oriunda da África do Norte, do Oriente Médio, do Subcontinente indiano, e em escala menor, da América Latina.

Do outro lado, alguns países tradicionais de imigração se transformam em áreas de emigração. Esse é, entre outros, o caso brasileiro. No Brasil, a inversão migratória começou na década de 1980 (Ripoll, 2008). O país sofreu uma perda líquida de aproximadamente 1,8 milhão de pessoas ${ }^{3}$ por meio de fluxos migratórios internacionais entre 1980 e 1990. Esse volume de emigração foi significativo e correspondia a 1,6\% da população residente no Brasil em 1990. O processo de conversão numa nação de emigração foi continuado na década seguinte. O saldo migratório internacional em anos 1991-2000 foi também negativo, estimado em 550 mil pessoas. Esse número correspondia a $0,4 \%$ da população brasileira em 2000 (Carvalho \& Campos, 2006). Houve então uma redução do fluxo migratório internacional nos anos 1990, porém a maioria dos 
emigrantes que deixaram o país na década de 1980 não voltou para o Brasil. Surge assim um significativo grupo de brasileiros no exterior, chamado por alguns autores de "diáspora brasileira". ${ }^{4}$ Em 2000, o número de emigrantes brasileiros, segundo dados estimativos do Itamaraty, alcançou quase dois milhões (Ripoll, 2008). Nos últimos anos, esse número quase dobrou: de acordo com estimativas de Itamaraty, em 2008 havia 3,7 milhões de brasileiros residindo no exterior. As principais áreas de residência são: América do Norte (principalmente Estados Unidos - 1,5 milhão), Europa (Espanha, Portugal, Itália e Grã-Bretanha - um milhão), América do Sul (especialmente Paraguai - 766 mil) e Ásia (especialmente Japão - 320 mil) (Fernandes \& Diniz, 2009).

A emigração dos brasileiros deve ser associada com a crescente interdependência entre nações e países, causada pela expansão do sistema econômico mundial (Sales, 1991). O progresso de meios de comunicação (internet, telefonia celular), a redução de custos de transporte (especialmente do transporte aéreo), a expansão das atividades das corporações transnacionais, a gradual redução dos obstáculos (tarifas e medidas não tarifárias, taxas de exportação, subsídios), facilitando a intensificação do fluxo de bens, serviços e de capital entre as economias nacionais, todos esses fatores contribuíram para a intensificação dos movimentos populacionais internacionais. A globalização exerce influência profunda na migração internacional. George Martine (2005, p.3) acentua que, para o emigrante contemporâneo,

seu horizonte é o mundo - vislumbrado no cinema, na televisão, na comunicação entre parentes e amigos. O migrante vive num mundo onde a globalização dispensa fronteiras, muda parâmetros diariamente, ostenta luxos, esbanja informações, estimula consumos, gera sonhos e, finalmente, cria expectativas de uma vida melhor.

Ainda que a globalização seja parcialmente inacabada, pois não existe um mercado de trabalho global, graças à crescente interdependência entre nações, a oferta e procura de mão de obra no Brasil foram enlaçadas com a economia mundial. Assim, existe a expectativa que a emigração dos brasileiros continuará como um fenômeno significante nos próximos anos (Fernandes \& Diniz, 2009).

O problema interessante, que está associado à migração, é o impacto econômico das deslocações internacionais para o país de origem. A conexão entre migração intrarregional (e também intrer-regional) e o desenvolvimento econômico foi profundamente explorada e pesquisada na literatura nacional brasileira, ${ }^{5}$ mas no nível de migração internacional permanece uma área de estudo relativamente nova. Portanto, existe a necessidade de assinalar as possíveis consequências da emigração para economia brasileira. O presente trabalho tem como principal objetivo descrever as vinculações entre a emigração e desenvolvimento econômico do país de origem no contexto brasileiro.

O texto está estruturado em quatro partes. A primeira tem um caráter introdutório, apresentando as principais teorias de migração internacional, relacionando-as com o processo de movimento populacional internacional do Brasil. A 
descrição dessas teorias tem sido absolutamente necessária na compreensão da evolução do fluxo migratório, mas também na análise das consequências econômicas da emigração, que é feita na segunda parte do artigo. A seguir, sintetizamse as mais importantes contribuições na área de migração e desenvolvimento, concentrando-se nos estudos que analisam os efeitos econômicos de remessas monetárias para regiões de origem. Finalmente, são relacionados esses estudos à situação do Brasil, apresentando dados atuais sobre as remessas, e as possíveis consequências do afluxo dessas para o país. Formula-se uma hipótese, de que no atual quadro emigratório, a economia brasileira deve se beneficiar das remessas oriundas da diáspora.

\section{As teorias da migração no contexto brasileiro}

Neide Patarra (2006) afirma que as teorias da migração internacional podem ser classificadas em dois grupos; no primeiro entram os modelos que determinam o surgimento do movimento internacional contemporâneo; no segundo estão as teorias que explicam a perseverança dos fluxos migratórios e a sua continuidade no tempo. Nesse sentido, deve-se começar a análise dos modelos teóricos que explicam a migração dos brasileiros a partir desses conceitos, que determinam como o movimento foi iniciado. Desse grupo, a mais conhecida é a perspectiva neoclássica, que destaca a desigualdade na distribuição internacional do capital e a mão de obra como o fator principal de movimentos populacionais no nível macroeconômico. Existem, portanto, países mais densos e mais rarefeitos de capital: enquanto as áreas abundantes de capital são os polos de atração para os migrantes, pois oferecem remunerações relativamente altas; as regiões com escassez desse fator de produção, nas quais os salários são baixos, se tornam os principais pontos de exportação da população (Massey et al., 1998). A abordagem neoclássica oferece também explicação do comportamento dos migrantes no nível micro: o deslocamento é o resultado do cálculo feito pelos fatores racionais, que pretendem de maximalizar suas necessidades. "O indivíduo migra porque espera um retorno financeiro que supere os gastos com a mudança e com investimentos em capital humano" (Fusco, 2005, p.16). Nesse quadro, não pode surpreender que nos anos 1980 no Brasil - naquele período um país de renda relativamente baixa - iniciou-se a emigração para os países ricos e industrializados, como Estados Unidos e Japão. A crise na economia nacional, contrastante com a situação relativamente boa nas economias dos países desenvolvidos, com certeza pode ser considerada fator que iniciou os fluxos migratórios. Esse movimento era entendido por muitos brasileiros como um investimento com retorno financeiro melhor, que oferecia carreira profissional nacional, já que a emigração era associada com o padrão de vida mais alto (Ferreira, 2007).

Segundo a nova economia de migração, o movimento populacional deve

ser analisado no contexto de imperfeições existentes no mercado de trabalho nos países em desenvolvimento (que são os maiores exportadores de mão de 
obra), mas também nos outros mercados: de capitais, de produtos rurais, ou educacional. Portanto, a unidade familiar, que nessa abordagem é considerada o principal agente econômico, tem a estratégia diferente daquela, que foi descrita na teoria neoclássica. Em vez de maximalizar suas necessidades, aqui o principal objetivo é a minimalização do risco econômico. Assim, a lógica de alocação de bens da unidade familiar procederá em diversificação dos disponíveis recursos. $\mathrm{O}$ principal recurso da unidade familiar é o trabalho. Dessa maneira, a diversificação significa que, numa família, alguns membros emigram para obter emprego no exterior, oferecendo um alternativo fluxo de renda para toda a unidade por meio de remessas monetárias (Stark \& Bloom, 1985).

Os pesquisadores que representam a abordagem da nova economia da migração ressaltam que o movimento populacional para o exterior é uma forma de investimento, portanto exige recursos que não são disponíveis em todas as unidades familiares. Os emigrantes não pertencem às mais pobres partes da sociedade - são aquelas pessoas que estão na situação de privação relativa ( relative deprivation - cf. Stark \& Taylor, 1989). As pessoas relativamente privadas sofrem com a recente redução de nível de renda. Em consequência, o padrão de vida desse grupo é mais baixo quando comparado com a situação anterior e com os grupos de referência. A migração pode contribuir para o aumento de renda e o melhoramento da posição econômica da unidade familiar na sociedade. A noção de privação relativa é absolutamente necessária na compreensão da migração dos brasileiros desde os anos 1980. Ricardo Ferreira salienta a dominação dos "limitados" nos fluxos migratórios para os Estados Unidos, Japão e países da Europa. Nesse grupo se encontram pessoas da "classe média empobrecida", que na situação de "impossibilidade de ascensão social [...] seriam os principais candidatos às migrações internacionais" (Ferreira, 2007, p.11).

Outra contribuição importante é a teoria do mercado dual de trabalho (Patarra, 2006), chamada também como teoria da segmentação do mercado de trabalho (Fusco, 2005). Proposta originalmente por Michael Piore (1983), destaca como fator principal dos movimentos populacionais internacionais as forças de atração nas sociedades de destino. Em países desenvolvidos existe a bifurcação do mercado de trabalho: no mercado primário estão disponíveis os empregos com altos salários e boas condições de trabalho. Já o mercado de trabalho secundário é instável, com remunerações baixas e condições de trabalho desfavoráveis. Portanto, os trabalhadores nativos rejeitam empregos no setor secundário. Nesse sentido, imigração aos países desenvolvidos é causada por uma demanda por mão de obra pouco qualificada: os imigrantes satisfazem essa demanda, aceitando empregos rejeitados anteriormente pelos nativos (Fusco, 2005).

A teoria do mercado dual é essencial para compreensão da imigração dos brasileiros para alguns países desenvolvidos, como Espanha ou Estados Unidos. Segundo Erika Ripoll (2008, p.162), os brasileiros empregados na Espanha são 
concentrados "em setores de atividades caracterizados por trabalhos precários, que não requerem qualificação e nem especialização profissional", como serviço doméstico e construção. Caracterizando a situação socioeconômica dos imigrantes brasileiros no Estado de Massachusetts (Estados Unidos), Ana Cristina Martes (1999) salienta que a grande maioria trabalha na faxina doméstica - um nicho de mercado com a dominação brasileira e feminina. Esses imigrantes "estão dispostos a aceitar essas ocupações porque os salários, quando comparados àqueles de seus países, são altos e o prestígio que se leva em conta é o de seu país de origem" (Ripoll, 2008, p.158). Vale acrescentar que os brasileiros no exterior, na sua grande maioria, trabalham ilegalmente, permanecendo clandestinamente no país receptor. ${ }^{6}$ Portanto, a orientação dos imigrantes brasileiros que trabalham no setor secundário está direcionada ao Brasil - é lá que mandam remessas, investem e se comparam com vizinhos em relação à sua posição socioeconômica.

Das teorias que explicam a perseverança dos fluxos migratórios e a sua continuidade no tempo deve-se ressaltar a importância das redes sociais, chamadas também de redes migratórias. As redes "são constituídas por laços que conectam migrantes, migrantes pioneiros e migrantes em potencial nas áreas de origem e destino por meio de relações de parentesco, amizade e origem comum" (Fusco, 2005 , p.22). Essas conexões facilitam o fluxo de capital e informação sobre as condições de vida e as possibilidades de emprego nas destinações. Dessa forma, ajudam os novos migrantes na adaptação no novo ambiente e tornam os futuros fluxos migratórios mais prováveis. $\mathrm{O}$ exemplo interessante, que mostra o funcionamento de redes, é o caso dos imigrantes brasileiros em Massachusetts, que vendem seus empregos de faxina doméstica. Quando uma imigrante está disposta a voltar ao Brasil, espalha-se a informação sobre a "venda" das casas, onde a faxineira trabalha, por meio das redes migratórias. A pessoa que compra o emprego é introduzida à dona da casa como a amiga da faxineira, que poderá substituí-la. A confiança e a solidariedade étnica entre os imigrantes brasileiras são reconhecidos como fatores principais, para que essa forma de transação possa ser finalizada (Martes, 1999).

Wilson Fusco (2005) aponta que a teoria das redes sociais é essencial na explicação do por que é que a migração dos brasileiros não ocorre de modo uniforme pelo território nacional. Existem portanto determinadas regiões de alta concentração de emigrantes, ligados pelas redes migratórias com específicas áreas de destinação. $\mathrm{O}$ exemplo mais conhecido na literatura nacional é o caso da cidade de Governador Valadares (Minas Gerais). A maioria de emigrantes provenientes dessa cidade chegou à Região Metropolitana de Boston, em Massachusetts. Analisando as redes sociais, Teresa Sales (1991) salienta o papel de igrejas evangélicas que, além de oferecerem serviço pastoral, exercem a função de intermediário entre região de origem e destinação, ajudando em busca do emprego ou nos problemas administrativos, orientando para tirar passporte ou visto. 


\section{Migração internacional e o desenvolvimento econômico: considerações gerais}

Analisando a relação entre os movimentos populacionais e desenvolvimento, aparece a questão fundamental: qual é a direção do relacionamento entre esses dois processos? No debate sobre impactos econômicos de migrações existia a falsa pressuposição de que os movimentos populacionais eram causados pela ausência de desenvolvimento: os homens emigravam de certas regiões pobres, onde não havia possibilidade de ascensão social, direcionando-se às áreas desenvolvidas. Porém, migração internacional, que vinculava regiões emissoras e receptoras, devia proporcionar o crescimento econômico da área de origem graças a remessas e investimentos da diáspora. Em consequência, o desenvolvimento econômico na região emissora devia reduzir a migração. Essa linha de pensamento está ainda presente na política migratória dos países desenvolvidos, especialmente os membros da União Europeia. Estados como Espanha ou Itália enfrentam um desafio de maciça imigração irregular. Portanto, implementam nas suas políticas migratórias o "regime de encerramento e coarctação" (Nyberg-Sørensen et al., 2002): os programas de assistência oficial para o desenvolvimento são oferecidos e direcionados àqueles países (especialmente da África subsaariana) que admitem os imigrantes ilegais entregados pelas autoridades europeias. Esses programas têm como um objetivo principal criar empregos na região emissora, limitando assim a migração à Europa.

As teorias de migração, como a referida nova economia de migração, apontam, no entanto, que não são os mais pobres que emigram. A migração, especialmente internacional, deve ser considerada como uma forma de investimento: é associada com risco e exige recursos próprios, os quais as pessoas pobres não possuem. "Países e regiões pobres frequentemente exibem baixas taxas de migração, enquanto estes que participam de maneira ativa no sistema global podem ser caracterizadas pelos altos níveis de migração e mobilidade" (Skeldon, 2008, p.5). Portanto, no começo o fluxo migratório é dominado pelos indivíduos que pertencem, como no caso brasileiro, à "classe média empobrecida", então o grupo que pode financiar sua migração. O gradual desenvolvimento econômico na área de origem é associado com o progresso na educação e enriquecimento da população. Dessa maneira, cresce o grupo que dispõe de recursos financeiros e acesso a informações necessárias para emigrar.

Alguns pesquisadores, como Hein De Haas (2009), salientam que a migração deve ser considerada como um processo naturalmente vinculado com e constituindo a parte de um processo mais amplo, ou seja, o desenvolvimento econômico. O desenvolvimento exerce influência profunda sobre a migração, o fenômeno que é descrito na literatura como "elevação migratória" (migration hump). Nos estágios iniciais do crescimento econômico, com o aumento de renda per capita, eleva-se o nível de migração. Com o enriquecimento da população, cresce o número de pessoas que tem renda suficiente para sustentar custos 
de viagem e acomodação na nova destinação. Somente nos países de renda alta, ou seja, no estágio de desenvolvimento avançado a emigração está diminuindo; ao mesmo tempo, aumenta a imigração (Figura 1). Nesse sentido, a evolução do padrão migratório no Brasil confirma a hipótese de "elevação migratória". Nos anos 1980 e 1990, quando começou o processo de emigração, o país era considerado uma economia de renda baixa. Assim, o nível de migração internacional era ainda modesto. No entanto, o desenvolvimento dinâmico da economia brasileira nos últimos anos deve estimular migração internacional dos brasileiros, o fato que já pode ser observado, pois nos anos 2000-2008 o número de emigrantes brasileiros cresceu de 2 milhões para 3,7 milhões.

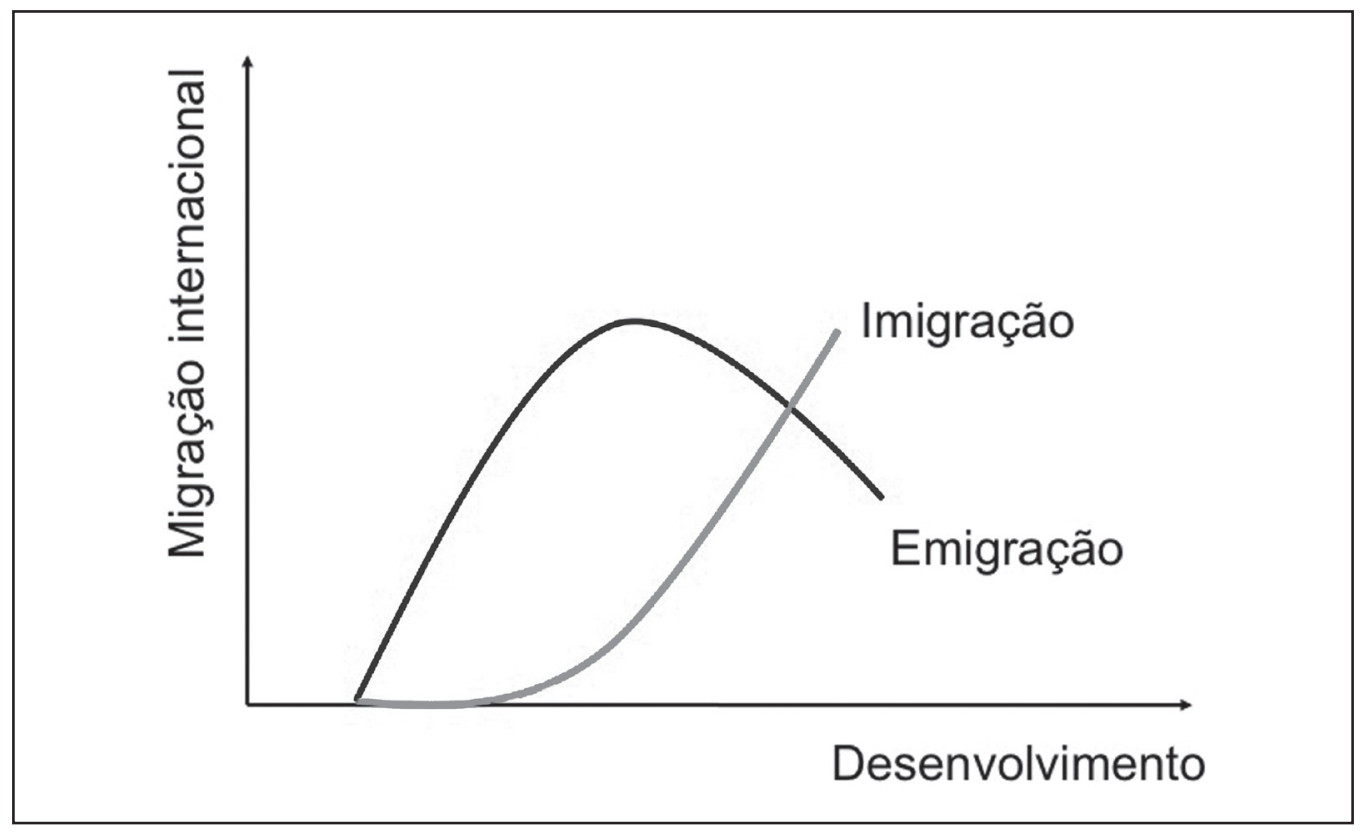

Fonte: De Haas (2009).

Figura l - Relação entre migração internacional e desenvolvimento.

Então, deve-se acrescentar que o relacionamento entre esses dois processos tem um caráter complexo. A migração pode influenciar o desenvolvimento econômico do país de origem, mas também o desenvolvimento econômico como foi demonstrado no caso brasileiro - exerce influência sobre a migração. Essa questão se torna ainda mais importante quando percebemos que nos últimos anos a migração é percebida como um fenômeno que pode ser gerido e usado na política econômica de países emissores. A crescente popularidade da orientação pró-migratória de algumas economias em desenvolvimento pode ser atribuída ao fenômeno do transnacionalismo. $\mathrm{O}$ transnacionalismo pode ser definido como "um processo no qual os imigrantes criam e mantém relações multidimensionais sociais que enlaçam suas sociedades de origem e de destinação" (Bash et al., 1994, p.7). "O progresso em transportes e comunicações aproxima 
os locais de origem e destino dos migrantes" facilita a atividade transnacional, possibilita a existência de múltipla identidade dos transmigrantes (Geiger, 2000, p.215).

Cresce, portanto, o número de países de emigração que procuram mobilizar o potencial de diásporas, percebendo-a como a força contribuinte para o desenvolvimento nacional. Os governos tentam facilitar e dinamizar a atividade transnacional, oferecendo aos migrantes privilégios e concedendo direitos especiais (Nyberg-Sørensen et al., 2002). Esses instrumentos incluem: redução parcial de impostos, rápidos procedimentos administrativos, facilidades infraestruturais e oportunidades para os investidores, programas de reintegração para os migrantes que retornam ao país emissor. Salienta-se a importância das associações dos migrantes, que além de fornecerem conselho podem se envolver diretamente nos programas de desenvolvimento nas comunidades de origem (Zoomers et al., 2008).

Todos esses esforços que tentam incluir migração na política econômica são associados com a suposição que a emigração pode contribuir positivamente para o desenvolvimento do país de origem dos imigrantes. Essa abordagem otimística está dominando na discussão econômica nos últimos 15-20 anos. Porém, existe também o enfoque pessimístico, com a pressuposição de que emigram os individuais mais aptos: jovens, empreendedores, trabalhadores altamente qualificados. Considerada assim, a migração é um fenômeno associado com o detrimento para os Estados emissores, contribuindo para a agravamento da pobreza. Essas abordagens contraditória estão presentes na análise da relação entre o desenvolvimento econômico e o movimento populacional no quadro internacional desde os anos 1960 (De Haas, 2008). Já que é impossível analisar todos os aspectos dessa discussão num simples artigo, na próxima seção analisaremos o aspecto mais conhecido na literatura de migração e desenvolvimento - $\mathrm{o}$ impacto das remessas monetárias sobre a economia do país emissor.

\section{Remessas monetárias e desenvolvimento do país de origem}

O mais evidente e visível efeito econômico da emigração para o país de origem dos imigrantes é o afluxo das remessas monetárias. ${ }^{7}$ Esse afluxo é a consequência da estratégia descrita nas teorias de migração - mais precisamente, na nova economia da migração. A unidade familiar diversifica os recursos disponíveis: alguns membros emigram para obter emprego no exterior. Os emigrantes contribuem para o orçamento familiar das pessoas remanescentes no país de origem, transferindo a parte dos seus salários. Eles também realizam a estratégia individual de diversificação dos recursos, investindo parte do capital poupado no país de origem e parte na destinação. Nesse contexto, as remessas devem provocar impactos econômicos consideráveis no nível micro, nas áreas de emigração (Taylor, 1999).

As consequências econômicas das remessas, no entanto, devem ser visíveis também no nível macro, levando em consideração que o fluxo de recursos dos 
imigrantes para os países emergentes tem crescido de maneira impressionantemente considerável nos últimos quarenta anos (Figura 2). Em 1970, todos os países emergentes ${ }^{8}$ recebiam apenas US\$ 405 milhões, e os países da América Latina e Caribe - a região de maior recebimento -, US\$ 51 milhões. Em 1990, esses números subiram para US\$ 31 bilhões e US\$ 5,7 bilhões, respectivamente. Em 2008, o influxo bruto de remessas para os países emergentes atingiu US\$ 338 bilhões, o número que constituiu $2 \%$ do Produto Interno Bruto dessas economias. Os países da América Latina receberam nesse ano US\$ 64,7 bilhões de remessas, que constituíam 1,8\% de seus PIB (Ratha et al., 2009). Mesmo com a recente redução do afluxo das remessas, em razão da crise financeira mundial, esses números são impressionantes. ${ }^{9}$ Portanto, deve-se levantar a questão se as remessas de recursos dos imigrantes podem afetar positivamente as economias de países de emigração.

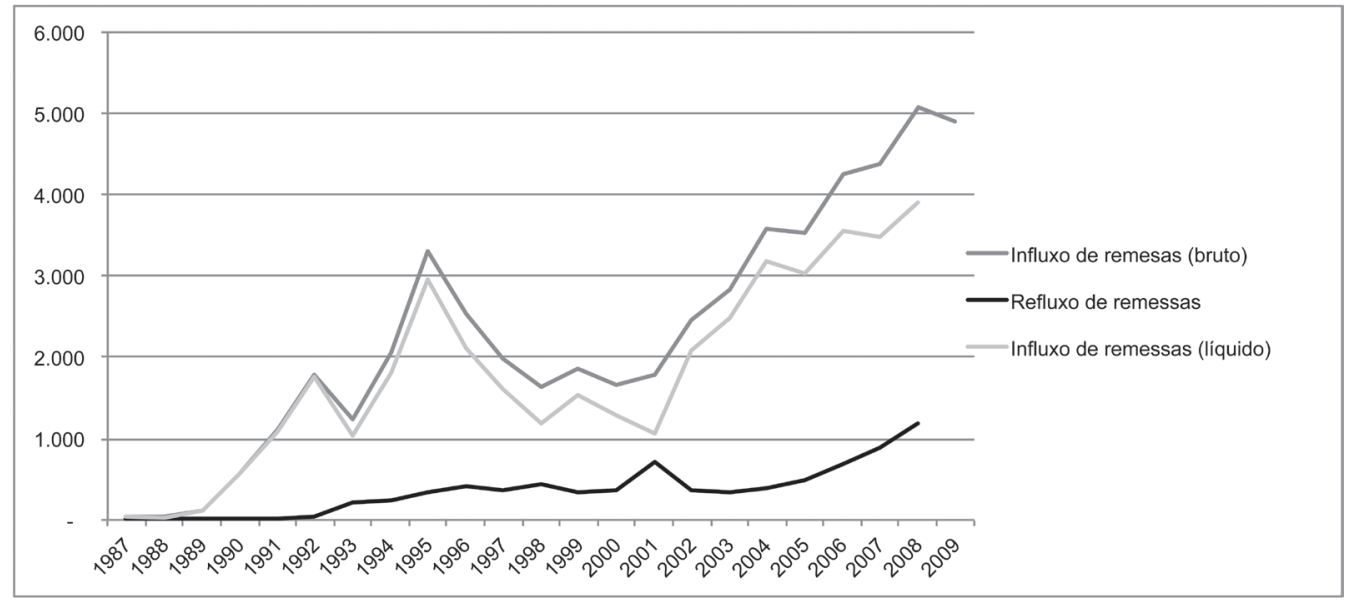

Fonte: Ratha et al. (2009). Os dados para o ano 2009 são apenas estimativos.

Figura 2 - Influxo de remessas monetárias (bruto) para os países emergentes: 19702009 (US\$ milhões).

$\mathrm{Na}$ discussão em torno de implicações econômicas das remessas devem-se destacar duas abordagens contraditórias: a otimística e a pessimística. O enfoque otimístico salienta que as remessas podem contribuir para a formação do capital humano, por meio de investimentos em educação ou saúde. Esse tipo de transferências pode ser denominado como remessas produtivas (Canales, 2005): elas podem também proporcionar um aumento de investimentos privados em capital físico, porque os emigrantes criam empresas e novos lugares de trabalho. Assim, em vez de influenciar a economia da maneira temporária, as remessas constituem um fator importante para o desenvolvimento econômico em longo prazo, aumentando a renda per capita e reduzindo a pobreza. Esses efeitos positivos deverão ser visíveis tanto no nível micro como no macroeconômico (Ghosh, 2006). 
Existe também, no entanto, uma abordagem pessimística que aponta que é duvidoso que as remessas podiam causar efeitos positivos em situações em que "tanto as políticas do estado, como as ações de mercado haviam fracassado sistematicamente" (Canales, 2005, p.3). Apenas uma pequena parcela de recursos transferidos do exterior é usada de maneira produtiva, pois "as remessas estão sendo direcionados principalmente para despesas correntes do dia-a-dia [...] ou seja, o dinheiro é usado para aquisição dos bens de consumo de curto prazo" (Martes \& Soares, 2006, p.41). Isso acontece em razão do grande grau de pobreza no qual as famílias de emigrantes se encontram. Portanto, no nível micro, as remessas ajudam a manter um mínimo padrão de vida, mas não constituem força suficiente para a promoção de mobilidade social (Oliveira Vidal, 2008). O estável afluxo de recursos do exterior para unidade familiar pode desmotivar aqueles que permaneceram. Portanto, as famílias de emigrantes podem trabalhar menos do que teriam feito se não tivessem o dinheiro transferido por diáspora. Assim, existe perigo de dependência estrutural dessas famílias de ajuda financeira dos emigrantes (Fajnzylber \& López, 2008). No nível macro, o afluxo de remessas pode contribuir para a "elevação da reserva de moeda estrangeira, que pode gerar valorização da moeda nacional, o que por sua vez interfere na lucratividade da exportação dos produtos manufaturados" (Oliveira Vidal, 2008, p.13-14), o conceito econômico conhecido na literatura como a "doença holandesa" (Dutch disease - Taylor, 1999).

Os estudos empíricos sobre os efeitos econômicos das remessas demonstram resultados contraditórios. No nível macro, algumas pesquisas indicam que não existe evidência de que remessas recebidas por um país afetem positivamente a taxa de crescimento econômico. Esse foi o caso do estudo efetuado por Nicola Spatafora (2005), que analisou 101 países em desenvolvimento nos anos 1970-2003. Esse estudo demonstrou que não existe uma relação estatisticamente significante entre o volume de remessas e gastos em educação ou saúde, nem entre as remessas e os investimentos. Da mesma forma, essa relação não podia ser comprovada no caso da taxa do crescimento, até em caso de países nos quais as remessas constituíam mais de $1 \%$ do PIB. O autor concluiu que o impacto das remessas sobre o desenvolvimento tem um caráter complexo e indireto, portanto, é muito difícil evidenciá-lo nos estudos macroeconômicos (Spatafora, 2005).

A tentativa de demonstrar a contribuição indireta das remessas no desenvolvimento econômico está presente no estudo de Giuliano \& Ruiz-Arranz (2009). As autoras analisaram a relação entre o afluxo de remessas e o crescimento econômico, incluindo a efetividade do setor financeiro dos países de origem dos imigrantes. A pesquisa, realizada nos setenta países emergentes nos anos 1975-2002, demonstra que as remessas podem afetar positivamente a taxa de crescimento econômico quando se levam em consideração as variáveis que descrevem o nível de desenvolvimento do sistema financeiro nacional e a efetividade do mercado de crédito. Nos países onde o acesso ao crédito é difícil ou 
custoso, os recursos transferidos pelos imigrantes constituem uma fonte alternativa de financiamento dos investimentos. Nesse grupo de economias, a relação entre remessas e taxa de crescimento foi positiva e estatisticamente significante. Ademais, nos países com baixo nível de desenvolvimento do setor financeiro, as remessas têm um caráter pró-cíclico, ou seja, crescem quando aumentam as possibilidades do investimento, durante o boom econômico (Giuliano \& Ruiz-Arranz, 2009).

O debate entre as abordagens pessimística e otimística está visível também nas pesquisas que analisam os efeitos econômicos das remessas na América Latina e Caribe. No estudo empírico efetuado em quatro países latino-americanos (México, Colômbia, El Salvador e República Dominicana) nos anos 1980-2004, Alejandro Canales $(2005$, p.6) salienta que "não há evidência estatística que permita definir as remessas como a fonte de investimento produtivo". Segundo o autor, as remessas produtivas na América Latina constituem apenas $5 \%$ do afluxo total de transferências. Mesmo com a duplicação da proporção de remessas produtivas para o $10 \%$ do total, elas "representariam apenas $1 \%$ de investimentos privados no México, menos de 2,5\% em Colômbia e Equador, menos de 5\% em República Dominicana, Guatemala, Honduras e Nicarágua e menos de 8\% em El Salvador e Haiti" (ibidem, p.23). Ao contrário do que foi comprovado por Giuliano \& Ruiz-Arranz (2009), Canales (2005) aponta que no seu estudo as remessas demonstram caráter anticíclico e aumentam seu volume em situações de crise econômica. ${ }^{10}$ Ademais, o efeito positivo de remessas, notavelmente a sua contribuição na redução de pobreza, é limitado: nos oito países analisados (México, Guatemala, El Salvador, Honduras, Nicarágua, República Dominicana, Equador e Peru), elas possibilitaram reduzir a taxa de pobreza em menos de 1,5 ponto percentual.

O estudo de Acosta et al. (2008) demonstra, no entanto, que as transferências de recursos dos imigrantes podem ajudar consideravelmente na redução de pobreza. A análise empírica feita pelos autores abrangeu 59 países emergentes nos anos 1970-2000. Para todos os países da América Latina e Caribe, o aumento do afluxo de remessas por um ponto percentual era em média associado com a redução de pobreza ${ }^{11}$ por $0,37 \%$. Dessa forma, as remessas reduziam o número de pessoas vivendo por menos de um dólar por dia por 35\% na República Dominicana, 36\% em El Salvador e 40\% no México.

Nos níveis mezo (regiões) e micro (comunidades locais), as pesquisas sobre os efeitos econômicos de remessas também mostram um quadro não unilateral. De um lado, as análises mostram que as famílias de emigrantes gastam os recursos obtidos no exterior em consumo, muitas vezes comprando bens de luxo, que são importados. Por exemplo, no estudo de Slask Opolski, uma região de intensiva emigração de poloneses para a Alemanha e a Holanda, Romuald Jonczy percebe que a maioria dos serviços encomendados pelos emigrantes e suas famílias tem sua origem em outras regiões do país (construção de casas, re- 
paros), enquanto os bens comprados por esse grupo são, em sua maioria, importados da Alemanha (especialmente automóveis). O autor conclui que o dinheiro das remessas, em vez de circular na economia local e regional, estimulando o desenvolvimento econômico, volta à área onde foi ganho (Jonczy, 2006).

Deve-se também salientar que a produtividade das remessas e seu impacto sobre o desenvolvimento dependem especialmente das condições socioeconômicas existentes na região de emigração. Martes \& Soares $(2006$, p.50) acentuam que

as remessas monetárias, raramente, são usadas com propósito produtivo, o que se deve em larga medida à inexistência de ambiente propício a esse tipo de investimento: se o país de origem não oferece ambiente social, econômico e institucional favorável para que o migrante use seu capital econômico e humano produtivamente, parece irreal esperar que as remessas possam, por si mesmas, promover a redução da pobreza e o desenvolvimento local.

O que é “produtivo", portanto, quando analisamos as despesas de recursos remetidos depende do contexto socioeconômico. No estudo efetuado na região de Oaxaca, México, Silvia Grigolini (2005) mostra que as remessas dos emigrantes podem ser usadas de maneira produtiva, mesmo se os gastos de unidades familiares podem ser classificados como a compra dos bens de luxo. $\mathrm{O}$ que no primeiro momento podia ser visto como consumo desnecessário se tornava investimento que trazia lucro: automóveis trazidos do exterior eram usados como táxis; geladeiras e aparelhos de televisão faziam parte de um bar. A mulher que recebeu um aparelho telefônico de seu filho - imigrante nos Estados Unidos - abriu um posto telefônico oferecendo seu número a todos que precisavam dele, e cobrando uma pequena provisão pelo serviço (Grigolini, 2005). Essas descobertas foram possíveis somente porque a autora passou muito tempo nas comunidades locais, conversando com os habitantes e observando suas atividades. A conclusão é simples: querendo avaliar o efeito econômico das remessas no nível local, não basta somente analisar os dados sobre o consumo; é necessário estudar a consumação dos habitantes no contexto local, como também observar como esses bens são utilizados.

\section{Remessas e a economia brasileira}

O Brasil é um dos principais recebedores de remessas na América Latina: o influxo de transferências, segundo os dados do Banco Mundial, aumentou de maneira considerável no final dos anos 1980, alcançando US\$ 1,1 bilhão no ano 1991 (Figura 3).

Deve-se acrescentar que o fluxo desses recursos tem caráter bilateral: dinheiro que imigrantes remetem para suas famílias no país, mas também os membros de família que permaneceram ajudam os imigrantes no exterior. Essa ajuda financeira é intensificada especialmente nas situações de crise econômica na destinação: por exemplo, no ano 2001, quando houve a redução do PIB dos Estados Unidos (a principal destinação para os imigrantes brasileiros) de 0,8\%, o 
refluxo de remessas do Brasil quase dobrou em relação ao ano anterior (2000), atingindo US\$ 709 milhões. Portanto, analisando os possíveis impactos de remessas para a economia brasileira, é preciso considerar o influxo líquido, ou seja, influxo bruto subtraindo o refluxo. Esse alcançou o pico em 2008: eram US\$ 3,9 bilhões. Em 2009, por causa da crise financeira da economia global, o fluxo de remessas reduziu consideravelmente - as estimativas para esse ano, que incluem apenas influxo bruto, demonstram diminuição de remessas para o Brasil de 3,5\% em relação ao ano anterior (Ratha et al., 2009).

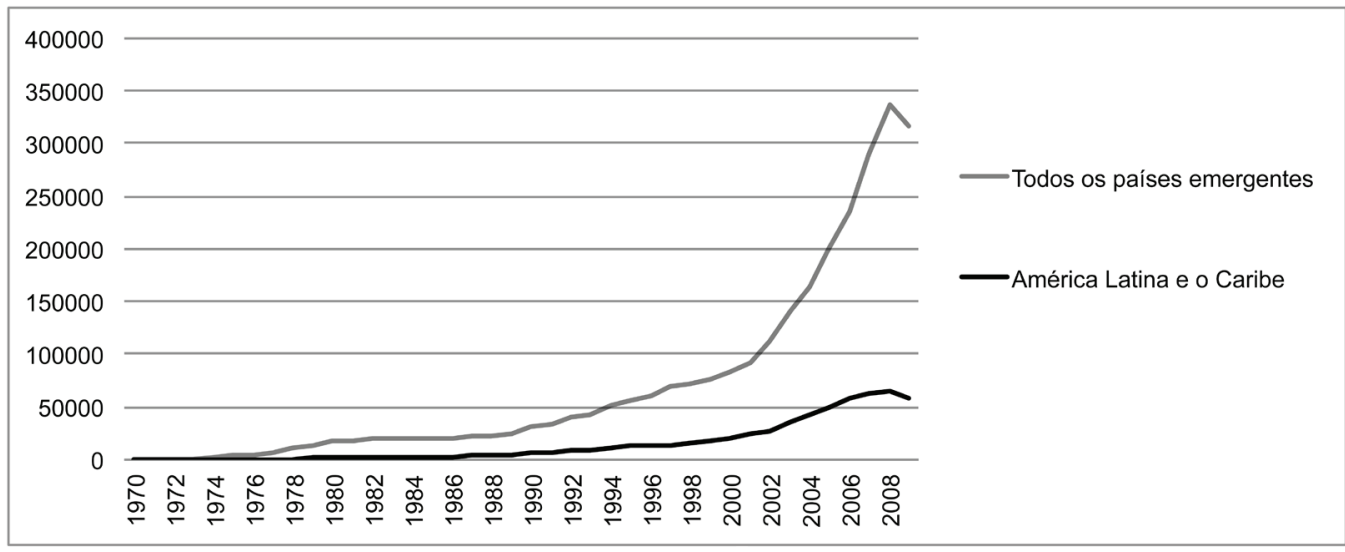

Fonte: Ratha et al. (2009). Os dados para o ano 2009 são apenas estimativos; no momento da publicação eram disponíveis somente dados sobre o influxo bruto de remessas nesse ano.

Figura 3 - Influxo de remessas monetárias para o Brasil: 1987-2009 (US\$ milhões).

Neide Patarra (2006) aponta que transferências dos recursos de imigrantes contribuem significantemente para a diminuição do desequilíbrio da balança de pagamentos. De acordo com os dados apresentados pelo Banco Interamericano de Desenvolvimento, US\$ 5,8 bilhões de remessas (influxo bruto) que entraram no Brasil em 2003 representavam 7\% das exportações brasileiras. ${ }^{12}$ Patarra afirma que transferências dos recursos de imigrantes superaram as exportações de soja (US\$ 4,3 bilhões em 2003) e do café (US\$ 1,3 bilhão). Dessa maneira, “o emigrante continua sendo o maior produto de exportação do Brasil" (ibidem, p.30).

Cumpre, no entanto, ressaltar que as remessas para o Brasil, mesmo alcançando valores impressionantes nos últimos anos, formam uma pequena fração da economia nacional, constituindo apenas $0,3 \%$ do PIB em 2008. Portanto, alguns pesquisadores apontam que em caso de grandes países-receptores de remessas como o Brasil, o peso das remessas no nível macroeconômico é limitado (Canales, 2005). Outros autores ressaltam que, em razão da grande dispersão de remessas pelo território brasileiro, "parece razoável admitir efeito virtuoso pouco significativo na dinâmica econômica das grandes cidades - São Paulo, Belo Horizonte e Vitória" (Martes \& Soares, 2006, p.50); já o efeito benéfico 
pode ser considerável nas regiões de intensiva emigração, como as cidades de Governador Valadares (MG), Criciúma (SC) e Maringá (PR). Segundo Wilson Fusco (2005), das remessas mandadas para essas cidades, uma das principais finalidades era o investimento que variava entre 16\% (Criciúma) e 19\% (Maringá) do montante.

O estudo de Weber Soares (Martes \& Soares, 2006) demonstra que na economia da cidade de Governador Valadares (MG) o fim produtivo das remessas era ainda maior: $38 \%$ dos recursos transferidos eram aplicados em compra, construção ou reforma de imóveis. Portanto, as remessas influenciaram de maneira considerável o mercado imobiliário: $35,9 \%$ de transações no período 1984-1993 eram realizadas pelos emigrantes. Soares afirma que os emigrantes valadarenses obtiveram um avanço social na comunidade de origem, passando a ocupar a posição de investidores. Esses investimentos dos emigrantes contribuíram para o desenvolvimento econômico local: no período 1991-1996, o PIB do Estado de Minas Gerais registrou a taxa de crescimento de 3,2\% ao ano, enquanto em Governador Valadares o PIB crescia num passo de $6,1 \%$. O autor sinaliza que esse desenvolvimento dinâmico deve ser atribuído ao "boom da construção civil, gerado pela poupança enviada do exterior pelos emigrantes internacionais de Valadares" (Martes \& Soares, 2006, p.47).

Os estudos nacionais demonstram que no Brasil as remessas produtivas constituem a parte importante do afluxo total de transferências, o número consideravelmente maior do que o médio uso produtivo das remessas na América Latina (5\% do montante), estimado por Alejandro Canales (2005). Portanto, pode-se alegar que, no caso brasileiro, as remessas contribuem de maneira positiva para o desenvolvimento econômico. Com o aumento da emigração do território nacional, que deverá ser continuado nos próximos anos, existe a expectativa de que a importância das remessas como um fator positivo para economia brasileira ainda crescerá. No entanto, esses efeitos benéficos não são visíveis em nível macroeconômico (economia nacional), mas sim em nível mezo, ou seja, as principais regiões de intensiva emigração, com especial ênfase em Governador Valadares.

Ademais, o efeito positivo de remessas pode ser ainda maior, se levarmos em consideração o contexto socioeconômico das comunidades onde o dinheiro mandado do exterior é gasto. Nas regiões pobres, onde o acesso ao crédito é difícil, recursos remetidos constituem uma fonte alternativa de financiamento dos investimentos. Como demonstrou Silvia Grigolini no estudo sobre as remessas no Estado de Oaxaca, no México (descrito na seção anterior), os recursos oriundos de remessas que inicialmente poderiam ser classificados como consumo desnecessário, depois de cautelosa análise podem emergir como investimentos produtivos. Porém, no Brasil esses efeitos positivos escondidos de remessas somente podem ser descobertos com estudos profundos, realizados em nível microeconômico nas áreas de maior concentração das famílias dos emigrantes. 
O uso produtivo de remessas no Brasil está também limitado pela inexistência de ambiente social e institucional favorável a esse tipo de investimento. Portanto, existe a necessidade da introdução das políticas em âmbito federal, estadual ou municipal, que promovam o uso produtivo de remessas. O exemplo da estratégia que teve resultados positivos é o programa desenvolvido pelas associações de emigrantes do Estado de Zacatecas (na parte centro-norte do México). Essas associações, em colaboração com o governo estadual de Zacatecas e o governo federal, desenvolveram programas de investimento em infraestrutura nas comunidades de origem dos emigrantes. O nome do projeto é " $3 \mathrm{xl}$ " (três por um), por causa do sistema de financiamento: a cada peso transferido pelas associações de emigrantes, os governos estadual e federal contribuem com adicional de um peso. Com esse dinheiro foram construídas estradas, escolas e hospitais nas comunidades locais. $\mathrm{O}$ fator mais importante, que contribuiu para o sucesso desse programa, não é apenas o capital remetido pelos emigrantes, mas também o envolvimento da diáspora no processo de identificação das necessidades de projetos infraestruturais, seu planejamento e supervisão. Portanto, os investimentos financiados com esse programa foram mais efetivos do que os projetos realizados pelo Estado (Kuznetsov \& Sabel, 2008). Esse tipo de política pode ser adaptado e transferido para o caso brasileiro, especialmente nas comunidades de intensiva emigração. Na diáspora brasileira, que neste momento constitui quase quatro milhões de indivíduos, existe um grande potencial, que pode ser usado para atrair os emigrantes às atividades econômicas produtivas e benéficas para as regiões de origem. A condição principal para que esse potencial possa ser liberado é o envolvimento mais ativo da classe política nacional nos problemas de diáspora brasileira.

\section{Notas}

1 Baseando-se nos censos brasileiros, Maria Stella Ferreira Levy (1974) ressalta que durante cem anos - entre 1872 e 1972 - entraram no Brasil cerca de 5,4 milhões de imigrantes; a grande maioria era de origem europeia (isto é, portugueses, italianos, espanhóis, alemães, poloneses, ucranianos e judeus).

2 Esse número é o resultado da projeção feita pelo Departamento de Assuntos Econômicos e Sociais (Desa, 2009) da Organização das Nações Unidas em 2009.

3 Nesse caso, os números referem-se a migrantes com dez ou mais anos de idade no ano de 1990 (Carvalho \& Campos, 2006).

4 Entende-se o conceito de diáspora no sentido proposto pelo Robin Cohen (1996), e introduzido na literatura brasileira por Neide Lopes Patarra (2006), ou seja: um grupo dispersado de seu país de origem rumo a (pelo menos) duas destinações no exterior que mantém nas áreas de imigração a particular identidade étnica. Esse grupo sustenta laços com país de origem, mas também entre as várias comunidades de compatriotas no exterior. Finalmente, a dispersão desse grupo foi originada pelo acontecimento trágico (guerra, golpe de Estado - migração forçada), ou por fatores econômicos 
(desenvolvimento do comércio, procura do emprego no exterior). Nesse sentido, os emigrantes brasileiros podem ser definidos como uma diáspora de trabalho.

5 As análises mais recentes veem os papéis apresentados durante o VI Encontro Nacional Sobre Migrações, da Associação Brasileira de Estudos Populacionais, 12 a 14 de agosto de 2009; por exemplo, estudo de Kleber Fernandes de Oliveira (2009) sobre a migração interna em Sergipe nos anos 1980-2000 e o impacto desse processo para o nível de pobreza nas áreas de origem e nas regiões destinatárias.

6 Por exemplo, Marcelo de Oliveira Vidal (2008) aponta que no caso de brasileiros na Espanha, 66,2\% estão em situação ilegal. Martes \& Soares (2006) afirmam que no grupo de entrevistados brasileiros na área metropolitana de Boston, nos Estados Unidos, $83 \%$ dos imigrantes declararam-se não documentados.

7 De acordo com a definição construída pelo Banco Mundial, pelas remessas monetárias entende-se um afluxo conjunto de 1) remessas de emigrantes, 2) compensação dos trabalhadores e 3) transferências dos emigrantes. As "remessas de emigrantes" são transferências dos trabalhadores que permanecem no exterior por mais de um ano, enquanto "compensação de trabalhadores" são transferências dos trabalhadores que permanecem no exterior por um tempo menor do que um ano. Enfim, "transferências dos emigrantes" são bens e ativos financeiros trazidos pelo emigrante quando ele (ela) ultrapassa a fronteira, por exemplo: o carro comprado no exterior (Ghosh, 2006).

8 Os países emergentes, segundo o Banco Mundial, constituíam em 2007 um grupo de 144 economias, que podiam ser adicionalmente divididas em três grupos: economias de baixa renda (low-income economies - 49 países em 2007), economias de renda média-baixa (lower-middle-income economies - 54 países) e economias de renda média-alta (upper-middle-income economies - 41 países).

9 Deve-se também salientar que os números apresentados são apenas os dados oficiais - a grande parte de remessas não está documentada, pois é transferida por meios não oficiais. As estimativas feitas pela Organização Internacioanal de Migração (IOM) mostram que remessas não documentadas constituem no mínimo 50\% do fluxo oficial (IOM, 2008).

10 Alejandro Canales analisa cada país separadamente, portanto em cada modelo macroeconômico o número de observações é modesto ( 25 observações). Ademais, a escolha de variáveis independentes é duvidosa, pois existe perigo de correlação entre a taxa de câmbio e a taxa do crescimento econômico. Dessa forma, os resultados dessa análise devem ser tratados com cautela.

11 O nível de pobreza era definido com a linha de pobreza mundial, ou seja, nível de renda inferior a um dólar por dia.

12 Os dados apresentados por Neide Patarra são os estimativos do Banco Interamericano de Desenvolvimento. Esses números são mais altos do que os dados apresentados pelo Banco Mundial. Porém, Neide Patarra está descrevendo o influxo bruto de remessas. Como foi comentado antes, no nível macroeconômico deve-se analisar o tamanho de remessas líquidas, que no caso brasileiro seria consideravelmente menor.

\section{Referências}

ACOSTA, P. et al. Do remittances lower poverty levels in Latin America? In: FAJNZYLBER, P.; LÓPEZ, J. H. (Ed.) Remittances and development. Lessons from Latin America. Washington DC: World Bank, 2008. p.87-132. 
BASH, L. et al. Nations unbound: Transnational projects, postcolonial predicaments, and deterritorialized nation-states. Langhorne, Pa.: Gordon and Breach, 1994.

BEINE, M. et al. Brain drain and economic growth: theory and evidence. Journal of Development Economics, v.64, p.275-89, 2001.

BEINE, M. et al. Brain drain and LDC's growth: winners and losers. IZA DP, n.819, 2003.

BHAGWATI, J.; HAMADA, K. The brain drain international integration of markets for professionals and unemployment: a theoretical analysis. Journal of Development Economics, v.1, p.19-42, 1974.

CANALES, A. Migración, remesas y desarrollo en America Latina: mitos y realidades. In: CONGRESSO ARGENTINO DE ESTUDIOS SOBRE INTERNACIONALES POLÍTICAS MIGRATORIAS Y DE ASILO. Conferencia Plenária II. Buenos Aires, 2005. p.1-33.

CARVALHO, J. A. M. de.; CAMPOS, M. B. de. A variação do saldo migratório internacional do Brasil. Revista Estudos Avançados, São Paulo, IEA/USP, v.20, n.57, p.55-8, maio/ago. 2006.

CASTLES, S.; MILLER, M. The age of migration. International population movements in the modern world. 4.ed. Basingstoke: Palgrave Macmillan, 2009.

COHEN, R. Diasporas and the State: from victims to challengers. International Affairs, v.72, n.3, p.507-20, July 1996.

D'COSTA, A. The international mobility of technical talent: trends and development implications. In: SOLIMANO, A. (Ed.) The international mobility of talent. Types, causes and development impact. New York, 2008. p.44-83.

DE HAAS, H. Migration and development: a theoretical perspective. International Migration Institute Working Papers, University of Oxford, n.9, p.1-61, 2008.

Migration transitions: a theoretical and empirical inquiry into the developmental drivers of international migration. In: XXVI IUSSP INTERNATIONAL POPULATION CONFERENCE. Marrakech, Morocco. 2 October 2009, p.1-49.

DESA. Trends in International Migration Stock: the 2008 Revision. Departamento de Assuntos Econômicos e Sociais da Organização das Nações Unidas. New York: United Nations, July 2009.

DOCQUIER, F. Brain drain and inequality across nations IZA DP, n.2440, 2006.

FAJNZYLBER, P.; LÓPEZ, J. H. The development impact of remittances in Latin America, In: _... (Ed.) Remittances and development. Lessons from Latin America. Washington DC: World Bank, 2008. p.1-20.

FERNANDES, D.; DINIZ, A. M. A. Brain drain or brain gain? In which direction does the Brazilian diaspora go? In: XXVI IUSSP INTERNATIONAL POPULATION CONFERENCE. Marrakech, Morocco. 30 September 2009, p.1-24.

FERREIRA, R. H. Migrações internacionais: Brasil ou Japão. O movimento de inserção do dekassegui no espaço geográfico pelo consumo. 2007. Tese (Doutorado) - Faculdade de Filosofia Letras e Ciências Humanas, Universidade de São Paulo. São Paulo, 2007.

FUSCO, W. Capital cordial: a reciprocidade entre os imigrantes brasileiros nos Estados 
Unidos. 2005. Tese (Doutorado) - Instituto de Filosofia e Ciências Humanas, Universidade Estadual de Campinas. Campinas, 2005.

GEIGER, P. P. Migrações internacionais e transnacionalismo na atualidade. Revista Brasileira de Estudos de População, v.17, n.1/2, p.213-16, 2000.

GHOSH, B. Migrants' remittances and development. Myths, rhetoric and realities. IOM. Geneva: The Hague Process on Refugees and Migration, Den Haag. 2006.

GIULIANO, P.; RUIZ-ARRANZ, M. Remittances, financial development and growth. Journal of Development Economics, v.90, p.144-52, 2009.

GRIGOLINI, S. When houses provide more than shelter. Analyzing the uses of remittances within their sociocultural context. In: TRAGER, L. (Ed.) Migration and economy. Global and local dynamics. Oxford: AltaMira Press, 2005. p.193-224.

IOM. World Migration 2008. Managing Labour Mobility in the Evolving Global Economy. Geneva: International Organization for Migration, 2008.

JONCZY, R. Exodus zarobkowy ludnosci autochtonicznej z województwa opolskiego i jego skutki. Polityka Społeczna, n.1, p.11-15, 2006.

KUZNETSOV, Y.; SABEL, C. Global Mobility of Talent from a Perspective of New Industrial Policy: Open Migration Chains and Diaspora Networks. In: SOLIMANO, A. (Ed.) The International Mobility of Talent. Types, Causes and Development Impact. New York: Oxford University Press, 2008. p.84-113.

LEVY, M. S. F. O papel da migração internacional na evolução da população brasileira (1872 a 1972). Revista Saúde Pública, São Paulo, v.8 (suplemento), p.49-90, 1974.

MACHADO, L. T. A teoria da dependência na América Latina. Estudos Avançados, São Paulo, v.13, n.35, p.199-215, 1999.

MARTES, A. C. B. Trabalhar em Massachusetts: um estudo sobre imigrantes brasileiros no mercado de trabalho. In: $2^{\circ}$ ENCONTRO NACIONAL SOBRE MIGRAÇÃO, Outo Preto. Anais... Ouro Preto, 1999, p.387-404.

MARTES, A. C. B.; SOARES, W. Remessas de recursos dos imigrantes. Estudos Avançados, São Paulo, v.20, n.57, p.41-54, 2006.

MARTINE, G. A globalização inacabada. Migrações internacionais e pobreza no século 21. São Paulo em Perspectiva, São Paulo, v.19, n.3, p.3-22, jul./set. 2005.

MASSEY, D. S. et al. Worlds in Motion. Understanding International Migration at the End of the Millennium. Oxford: Clarendon Press, 1998.

NYBERG-SØRENSEN, N. et al. The migration-development nexus: evidence and policy options. International Migration, v.40, n.5, p.49-71, 2002.

OLIVEIRA, K. F. de. Migração interna e pobreza na região da Grande Aracaju e no interior sergipano. In: VI ENCONTRO NACIONAL SOBRE MIGRAÇÕES. Associação Brasileira de Estudos Populacionais, 12 a 14 de agosto de 2009. p.1-25.

OLIVEIRA VIDAL, M. de. Migrações e remessas Espanha/Brasil: implicações, vantagens e desvantagens. In: XVI ENCONTRO NACIONAL DE ESTUDOS POPULACIONAIS. Associação Brasileira de Estudos Populacionais. Caxambu, 2008, p.118.

PATARRA, N. L. Migrações internacionais de e para o Brasil contemporâneo: volumes, 
fluxos, significados e políticas. São Paulo em Perspectiva, São Paulo, v.19, n.3, p.23-33, jul./set. 2005.

PATARRA, N. L. Migrações internacionais: teorias, políticas e movimentos sociais. Estudos Avançados, São Paulo, v.20, n.57, p.7-24, 2006.

PIORE, M. J. Labor market segmentation: to what paradigm does it belong? American Economic Review, v.73, n.2, p.249-53, 1983.

RATHA, D.; XU, Z. Migration and remittances factbook 2008. Herndon VA: World Bank, 2008.

RATHA, D. et al. Migration and remittance trends 2009. Migration and Development Brief, n.11, November 3, 2009, Development Prospects Group, World Bank.

RIPOLL, E. M. O Brasil e a Espanha na dinâmica das migrações internacionais: um breve panorama da situação dos emigrantes brasileiros na Espanha. Revista Brasileira de Estudos de População, v.25, n.1, p.151-65, 2008.

SALES, T. Novos fluxos migratórios da população brasileira. Revista Brasileira de Estudos de População, v.8, n.1/2, p.21-32, 1991.

SKELDON. Migration and development. Bangkok, Thailand: United Nations Expert Group Meeting on International Migration and Development in Asia and the Pacific, 20-21 September 2008, p.1-9.

SPATAFORA, N. Worker's remittances and development. World Economic Outlook, Washington DC, IMF, April 2005, Chapter 2.

STARK, O.; BLOOM, D. E. The new economics of labor migration. The American Economic Review, v.75, n.2, p.173-78, May 1985.

STARK, O; TAYLOR, J. E. Relative deprivation and international migration. Demography, v.26, n.1, p.1-14, Feb. 1989.

TAYLOR, J. E. International migration, remittances and development: myths and facts. International Migration, v.37, n.1, p.63-88, 1999.

WALLERSTEIN, I. The modern world-system: capitalist agriculture and the origins of the European World-Economy in the Sixteenth Century. New York: Academic Press, 1976.

ZOOMERS, A. et al. International migration and national development: An introduction to policies in sub-Saharan Africa. In: ADEPOJU, T. et al. (Ed.) International Migration and National Development in sub-Sabaran Africa. Viewpoints and Policy Initiatives in the Countries of Origin. Leuven: Koninklijke Brill, 2008. p.1-20.

RESUMO - O Brasil é um país com uma longa tradição imigratória, porém a emigração internacional é um fenômeno recente. A inversão migratória começou na década de 1980, quando a saída de brasileiros para o exterior evoluiu de maneira considerável. Esse processo foi continuado nas décadas seguintes, convertendo um típico país de imigração numa nação de emigração. Assim, surgiu a diáspora brasileira, estimada atualmente em 3,7 milhões de pessoas. A diáspora constitui um grande desafio para o país, especialmente em relação às consequências econômicas da emigração, visto que esses movimentos 
deverão ainda se intensificar. O presente trabalho tem como principal objetivo descrever as vinculações entre a emigração e desenvolvimento econômico de país de origem. Ao apresentar teorias de migração internacional, procede-se a uma análise dos estudos que analisam as consequências econômicas da emigração. A apresentação dessa contribuição teorética e empírica na área da economia de migração é necessária na compreensão do problema brasileiro. $\mathrm{O}$ autor formula uma hipótese de que no atual quadro emigratório a economia brasileira deve se beneficiar dos movimentos internacionais.

PALAVRAS-CHAVE: Emigração e desenvolvimento econômico, Desenvolvimento econômico do Brasil.

ABSTRACT - Brazil is a country of a long immigration history, however its emigration experience is a recent issue. The migration transition started in the 1980s, when the first wave of migration was initiated. This process is continued in the next decades: therefore, the traditional nation of immigration was transformed in the nation of emigration. Brazilian Diaspora is now estimated in ca. 3,7 million and constitutes an important area of interest for the scholars and policy-makers interested in development policy. This article focuses on the relationship between migration and development from the perspective of the sending country. The author argues that in the Brazilian case, the impact of migration on the national economy should be beneficial, especially when analyzing the effects of remittances on the mezzo (i.e. regional) level.

KEYWORDS: Migration and development, Economic development of Brazil.

Jan Brzozowski é doutor em Economia, professor adjunto da Faculdade de Economia e Relações Internacionais da Universidade de Economia de Cracóvia (Polônia). Desenvolve pesquisas na área de migrações internacionais e desenvolvimento.

@ - jan.brzozowski@uek.krakow.pl

Recebido em 4.1.2011 e aceito em 12.2.2011. 